\title{
Designing an Informed and Aware Behavioural Transition towards a Sustainable Food Life Cycle
}

\author{
Carmen Bruno ${ }^{a}$, Venere Ferraroa, Lucia Rampino ${ }^{a^{*}}$, Susanna Testa \\ aPolitecnico di Milano, Design Department \\ *Corresponding author e-mail: lucia.rampino@polimi.it
}

\begin{abstract}
:
Climate change is a global concern, standing as a key topic of the European Agenda. To ensure systemic changes towards a circular economy and achieve a low-emissions pathway, active public participation and confidence in the transition are essential. The paper reflects on such a challenge, drawing on co-design activities led by the Design Department of Politecnico di Milano and aimed at identifying actual possible research challenges and emergent research agendas, aligning them with 2030 European goals. Through co-design sessions, an international and multidisciplinary team devised a digital system to engage young citizens, increasing the environmental awareness of their eating habits. The finalization of the digital system design and its testing activity will leverage both design for behavioural change and the citizen sciences approaches. The paper emphasizes the strategic role of design in adopting an interdisciplinary and multi-layered approach to find a solution to complex issues, as the transition towards zero waste is.
\end{abstract}

\section{Keywords: Sustainable Food Life Cycle; Design for Behavioural Change; Citizen Science; Addressing Complexity}

\section{Introduction}

The paper presents the outcome of a co-design experience addressing one of the key issues of the 2030 European agenda: making Europe a climate-neutral continent.

The 2019 UN Sustainability Report ${ }^{1}$ highlighted that, despite the progress achieved in many areas, there is now a need for faster and more ambitious actions to achieve the economic and social transformation required to reach the SDGs. The most pressing need for action is the fight against climate change, the catastrophic and irreversible effects of which will occur - and in some cases are already being felt - if greenhouse gas emissions are not reduced. This will make many parts of the world uninhabitable, particularly affecting the most vulnerable countries and people. The UN Report

\footnotetext{
${ }^{1}$ https://unstats.un.org/sdgs/report/2019/The-Sustainable-Development-Goals-Report-2019.pdf 
highlights some strategic lines that can lead to significant progress, such as effective international cooperation in the multilateral perspective, better use of statistical data and the enhancement of science, technology and innovation, with a greater focus on digital transformation and education. More recently, the report "Progress towards the Sustainable Development Goals" ${ }^{2}$ reiterates the urgency of dramatically increasing the pace and scope of efforts over the next decade to achieve the SDGs. Within this framework and based on these assumptions, the case study presented here is an example of multidisciplinary and international collaborative design experience aimed at identifying inclusive solutions for citizens to educate them to adopt sustainable practices.

\section{A Co-Design Experience Towards Sustainability}

\subsection{Why}

The co-design research experience, led by design researchers belonging to the Design Department of Politecnico di Milano had the main scope of identifying possible relevant research challenges and emergent research agendas aligning them with the 2030 European goals. The invited co-designing actors were selected in accordance with

- the relevance of their expertise in relation to the challenge to be addressed;

- the presence of ongoing collaborations, partnerships and research projects - so to be able to make the most out the existing eco-system.

\subsection{Who}

The co-design team involved eleven (11) partners, among Universities and Schools, SMEs and Large Enterprises, Technology Centres, Policy Makers and Media Agencies. Such team relied on multidisciplinary and complementary expertise: researchers in design and engineering, software developers, IT solutions providers, and Al experts. The design leadership of such a tech-based team was established to be in line with the vision for a New European Bauhaus: "By creating places, environments and experiences [...] for prototyping and participation, the New Bauhaus can provoke and prompt Europe's imagination of the Green Deal, as a social, cultural, economic and political act as well as a technological one." (Bason et al., 2021, p. 11).

During the co-design activities, design was used as a lens to envision possible systemic inclusive solutions. Many scholars acknowledge design as strategic for envisioning solutions that consider citizens' demands and needs and the cultural context in which such requests and needs are generated. Design is indeed about understanding how to shape what is possible in a desirable manner, helping citizens take on new behaviours and attitudes to better act and live (Ranjan, 2009; Tromp and Hekkert, 2018).

\subsection{When and How}

The experience took place over four months, from September 2020 to January 2021, and was shaped through two main phases.

During the first one, the team confronted the ongoing activities, the results - in terms of tools and actions - generated by the two European initiatives Climate Adapt platform ${ }^{3}$ and Covenant of

\footnotetext{
${ }^{2}$ https://sustainabledevelopment.un.org/content/documents/26158Final_SG_SDG_Progress_Report_14052020.pdf

${ }^{3}$ https://climate-adapt.eea.europa.eu/
} 
Mayors ${ }^{4}$. What is more, the team members presented the knowledge and results gained through their previous experience in the field. This first phase was particularly helpful in framing the core challenges within the broader emergency of sustainability. In particular, the team members had an active role in relevant former EU-funded research projects that brought to the implementation of products and services intended to trigger a change in citizens' behaviours and generate social innovation.

The second phase, dedicated to co-design activities, was conducted through several multidisciplinary discussion sessions. The team members were involved in taking an active part, bringing their perspective to solve the design challenge. These sessions were conducted using web-based tools (Microsoft Teams) and recorded to track the progress and analyse the results. Each one-hour session was led and moderated by the project coordinator (i.e. a designer). Therefore, the presented output is the result of a design-driven action based on collaboration and integrated dialogue.

\section{The Challenge: Addressing Climate Change starting with a better Food Life Cycle}

During the first phase, through literature review and comparing data and results of previous and ongoing research, the team identified the macro and micro areas of interest to address the challenge. As a result, a specific framing of the problem was chosen, and the constraints and target users were defined.

Our planet is experiencing an increased and accelerated climate change caused by greenhouse gases (GHG), otherwise called carbon footprint, with severe consequences for our economies and societies. Carbon footprint reveals precisely the total amount of carbon emissions caused by human activities or through the life cycle of products: from their creation, transportation, and use to their destruction or wastage. In the EU, food is the second-largest contributor to our carbon footprints, and its impact on biodiversity needs to be lowered soon. Therefore, both citizens and producers must contribute within an international and national shift commitment towards sustainable food practices. As consumers, the most significant difference we can make is to change our diet, preferring foods with a lower environmental impact. There are, indeed, massive differences in the GHG emissions within the food realm, and animal-based foods tend to have a higher footprint than plant-based ${ }^{5}$. A survey ${ }^{6}$ conducted by the European Consumer Organization (BEUC) in 11 countries showed that environmental concerns influence EU citizens. They are willing to change their eating habits, with many prone to waste less food at home, buy more seasonal fruit and vegetables and eat more plantbased foods. However, price, lack of information, and the challenge of identifying sustainable food options and their limited availability are the main perceived barriers to sustainable eating. Moreover, young generations' concern for the environmental impact of their daily choices seems weak, especially when it comes to food. National and EU research (Diethelm et al., 2012) has shown a slight lack of interest in the food that young people consume daily. Those factors make citizens underestimate the environmental impact of their eating habits. Therefore, creating a sustainable food system is an opportunity at the European level to improve lifestyles, health, and preserve the

\footnotetext{
${ }^{4}$ https://www.covenantofmayors.eu/

5 Producing a kilogram of beef emits 60 kilograms of GHG CO2-equivalents while peas emit just 1 kilogram per kg (Ritchie and Roser, 2020).

${ }^{6} \mathrm{https} / / /$ www.beuc.eu/publications/beuc-x-2020-042_consumers_and_the_transition_to_sustainable_food.pdf
} 
environment, requiring active citizen participation, awareness-raising, and people's behavioural change.

Building on this ground, the co-design sessions had its perimeter on food, recognised as a strategic sample to move toward a more sustainable lifestyle, with Zoomers (from 8 to 27 years old) as the main target user. The team defined as its primary objective that of creating a network of young foodsavvy consumers who share their food values through peer-to-peer social media communication. In this way they would become healthy food influencers spreading the culture of healthy food.

\section{The Output: A Digitised User Experience}

As said, the second phase consisted in the actual co-design sessions aimed to identify possible solutions to foster social action towards more sustainable behaviours in food consumption, exploiting the potential of digital technologies. A total number of six (6) co-design sessions were performed involving thirty-two (32) participants.

Capitalizing on the team's expertise, experience in previous and ongoing funded projects ${ }^{7}$ and results of the co-design sessions, the team ideated a digitized system where citizens could input a picture of the food they are buying/cooking/eating/discarding, in turn receiving information and suggestions to make sustainable choices. The system could leverage the social aspect of food to meet the young generations' habits. Indeed, it would allow sharing on social networks pictures of dishes, recipes, video tutorials, joining and launching cooking challenges, giving and receiving approval feedback, and joining digital communities.

More in details, in our vision, the overall system (Fig. 1) would be composed by:

- the cross-platform FOODIE app able to calculate the carbon footprint of food through image recognition algorithms;

- FOODIE Citizen Web Platform that acts as a connection point of citizens with the FOODIE system and will permit the creation of the FOODIE community;

- a digital Communication Campaign to be displayed on Digital Totems to engage the largest possible number of citizens and increase collective awareness;

- a Social Rewarding system: a gamified system based on points, stickers and badges which will span across personal (i.e., mobile app/ web platform) and collective (i.e., web platform/digital totems) interfaces to foster the engagement of the entire stakeholders' network (i.e., restaurants, supermarkets, food markets etc.).

By taking a picture or scanning the QR code of food, citizens would receive immediate feedback on the average carbon footprint of said food, translated into intuitive equivalent terms. Moreover, an Al-based recommender system would provide citizens with personalized suggestions and propose

\footnotetext{
${ }^{7}$ For Citizens Engagement: SALL (https://cordis.europa.eu/project/id/871794), FoodSHIFT2030 (http://foodshift2030.eu), Open Schools for Open Societies - OSOS (https://www.openschools.eu), REINFORCE - Research Infrastructures FOR Citizens in Europe (https://www.reinforceeu.eu/), FIT4FOOD2030 (http://fit4food2030.eu/); for Behavioural Change: PROTEIN (https://protein-h2020.eu/), NUTRISHIELD (https://nutrishield-project.eu/), Nestore (https://nestore-coach.eu/home), PEGASO - Personalised Guidance Services for prevention of Obesity in teen-agers (www.pegasof4f.eu); for Policy Making: Big Policy Canvas (https://www.bigpolicycanvas.eu/cookies).
} 
alternatives for the future. Finally, a user-friendly data visualization system would allow citizens to keep track of signs of progress.

While monitoring and observing the carbon footprint of their everyday food consumption, citizens would develop an awareness of their footprint. As happened in several previous projects, this awareness might nudge them towards changing their habits and demanding more sustainable food products, sparking and triggering a switch towards sustainability in the entire food chain.

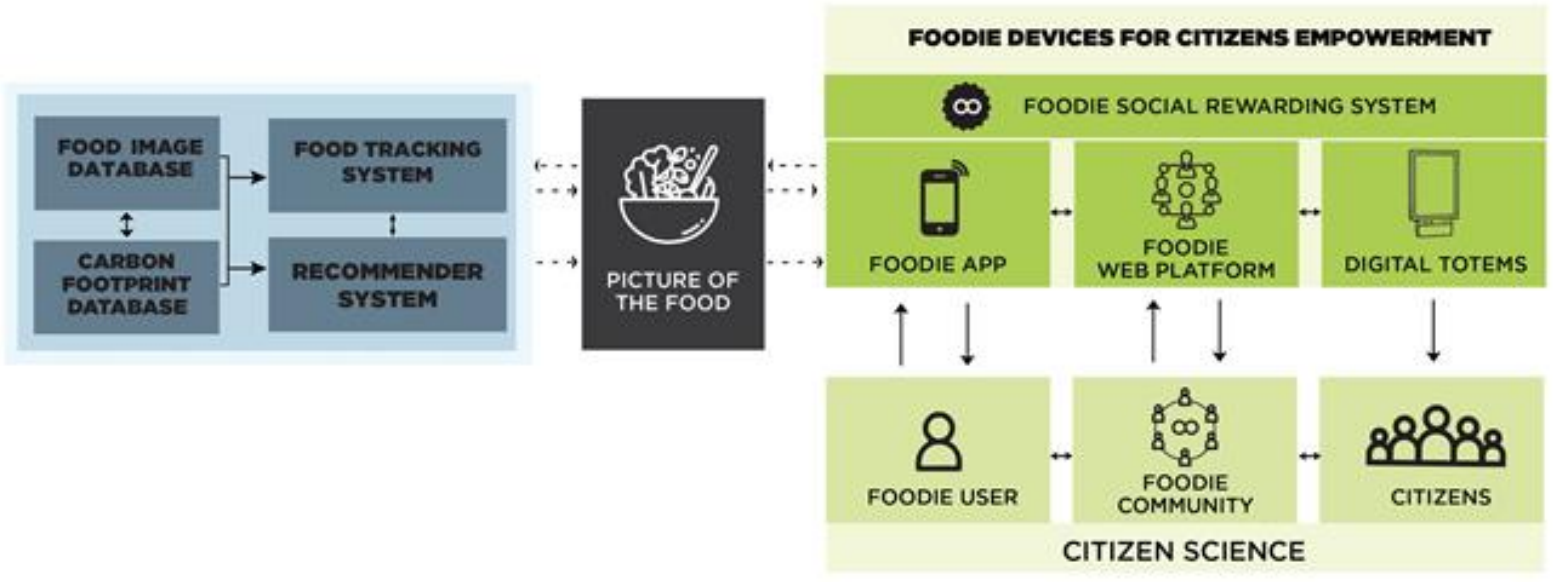

Figure 1: The FOODIE Overall System

\section{A Design-driven Set of Approaches}

By now, the multidisciplinary team has outlined the overall architecture of the FOODIE system, leveraging the knowledge and experience gained in previous projects.

If the team receives the fundings it applied for, a set of multi-layered approaches - and associated methods for implementing and testing FOODIE will be adopted: (i) the design for behaviour change approach; (ii) the citizen science approach; (iii) the community engagement approach.

\subsection{Design for Behaviour Change}

There is a growing understanding that design can intentionally affect users' behaviour to achieve a meaningful change related to sustainability goals (Herring and Roy, 2007; Tromp and Hekkert, 2018). To this end, in the implementation of FOODIE, the team will leverage design for behaviour change strategies (Cash, Hartlev, Durazo, 2017). In general, when designers are called on to design products intended to change user behaviour, there must be some reason why the desired behaviour is not the norm: what is best for the community is not always experienced as optimal for the individual. Thus, the designer's task is to deliberately address individual interests to stimulate socially desired behaviours (Tromp, Hekkert, Verbeek, 2011).

The behavioural strategy implemented in FOODIE will be based on:

- a non-authoritative instruction style, preferring a phrasing approach based on tips and suggestions rather than an authoritative one based on commands and characterized by high expectations of appropriate behaviour and evaluation criteria (Uibu and Kikas, 2014).

- cooperative and competitive social feedback - users, will both have the chance to work in teams, to take part in challenges and complete their objectives, or to play against peers and be motivated to achieve their goal by winning competitions and score points. 
- positive reinforcement: citizens will be persuaded mainly by adding constructive stimuli (e.g., positive notifications, reward points, level upgrades). They will be both extrinsically motivated by external factors (such as the possibility of winning a challenge, scoring reward points and receiving benefits) and intrinsically motivated by having a good feeling of themselves by engaging in sustainable actions and achieving set goals.

As already outlined, a key aspect in the FOODIE behaviour change strategy will be the role of the socalled taskification approach ${ }^{8}$ (Naeem et al, 2017, p. 631). This incorporates gamification features to increase citizens' engagement and motivation, while they conduct tasks such as doing food shopping, cooking or performing new challenges. Gamification is intended as the use of video-gaming design elements in a non-game context (Deterding et al., 2011). It has been defined as "a persuasive technology that aims to exert influence over human behaviour, which can be more powerful than monetary incentives". (Benner, Schöbel, Janson, 2021, p. 5).

Deterding et al. (2011) introduced a categorisation of game design elements based on seven factors: progress: elements that visualise the progress of an individual during the system use; pressure: elements that influence a user's behaviour not by a reward but by pressure or punishment whenever a task is not completed; rewards: for completing a task or activity; guidance: providing constant visual feedbacks to help to keep users aware of their progress or failures during the system use; competition: enabling users to challenge each other; collaboration: including elements that are given to users for successfully working with others; aspiration: refers to elements that challenge users to strive for something. In general, goals are used as specific design elements for challenging users. By exploiting those seven factors, the team ideated a taskification system with multiple features. The effectiveness of such a taskification system will be tested in specifically designed pilots.

\subsection{Citizen Science}

One of the main cores of the FOODIE system is both to inform and make citizens aware of the impact of their food choices, as well as let them participate in the production and exchange of relevant knowledge, by adopting a citizen science approach.

The advancement of digital technologies empowers citizens to be both involved in knowledge production (Maccani et al., 2020) and mobilized for collective engagement. Citizen Science is a powerful tool to understand "what society wants and needs" with the help of citizens' inputs (Figueiredo Nascimento et al., 2016). If we receive the fundings for testing and implementing FOODIE, we will adopt a citizen science approach based on:

- Data collection of environmental data - information related to food products will be collected by taking pictures and entering the specific data, such as the origin and type of the product. This will enrich the FOODIE database to calculate and provide more accurate information about food carbon footprints.

- Social learning/Knowledge production of food-related topics ("Wikipedia of Food") - citizens will be engaged throughout all stages of their food experience to contribute with concrete "Facts and Figures," nurturing FOODIE with their scientific knowledge. This process of civic involvement, learning, and education could foster innovation, a sense of ownership, and responsibility of the citizens to make their participation meaningful (Maccani et al., 2020).

\footnotetext{
8 Taskification is a task management application, which tracks the progress of tasks (e.g. coursework) and rewards the user with XP (experience points) once they reach certain milestones while completing the task (Naeem et al, 2017, p. 631).
} 
- Incentivising through gamification and rewarding - the gamification features might create incentives for science knowledge production and for science education for young generations. This aspect is intended to leverage the continuous engagement in citizen science activities.

The FOODIE approach to citizen science will ideally overcome the recognised obstacles concerning both quality and reliability and consistency of citizen science data (Maccani et al., 2020), by incentivising continuous knowledge production and reinforcing civic engagement with the help of devices features, the Social Rewarding system, and the Communication Campaign.

At this stage, all these are just assumptions, even if grounded on an extensive literature review and the team's solid experience. It will be crucial to test them throughout the project implementation, leveraging community engagement. The team is ready to abandon any of the described assumptions if the users' tests do not confirm them during the piloting activities.

\subsection{Community Engagement}

Community engagement is key in accelerating change and innovation, creating shared ownership of the outcomes to address environmental issues, and ensuring a long-lasting impact on project activities (Varumo et al., 2020). The overarching goal of such an engagement is to create social cohesion among citizens and stakeholders by reinforcing interactions in addressing the global challenge of food sustainability, which would enhance the social capital of citizens.

FOODIE aims at reaching community engagement and empowerment by activating:

1. Codesign workshops and pilots - all the elements of the system and the behavioural change strategies as described here will be presented to and discussed with citizens, so to finalise them and embed the FOODIE system in local cultures, embracing local issues and opportunities. Three pilots in three different countries (Italy, Spain and Greece) will test and refine the system.

2. Collective intelligence and knowledge sharing - creating good practices and new practical knowledge by sharing citizens' own recipes and video tutorials. This DIY civic engagement provides out-of-the-box thinking and turns citizens into "catalysers of innovation" (Nascimento et al., 2016, p.32).

3. Collective activities - engaging citizens to join challenges to reinforce their behaviour change and launch challenges to motivate food stakeholders to a transition towards more sustainable food services and productions leveraged by the FOODIE Social Rewarding System.

\section{Limits of the FOODIE System}

The outlined FOODIE system presents some limitations and implementation difficulties, largely due to the level of complexity of the project itself. In FOODIE, indeed complexity manifests itself on several levels.

Firstly, FOODIE tackles one of the most complex, yet urgent challenges posed by modernity: the need to use the available resources wisely, rethinking and redesigning shared consumption patterns.

Like any change, the transition from one condition to another is non-linear, entails resistance, inertia, and a tendency to preserve the original state. FOODIE is therefore also challenging in terms of objectives. To overcome the inertia of (young) citizens, the team will engage in a design-driven 
process based on three approaches: (i) design for behaviour change; (ii) citizen science; (iii) community engagement.

Complexity is also in the number of variables involved and in the degree of uncertainty underlying the cause-effect relationship: the dynamics of mutual influence among individuals and the users' engagement are highly unpredictable. Indeed, "People are notoriously nonlinear." (Ramo, 1969, p.97). Selecting and combining game design elements does not necessarily support the intended behavioural change of users. A continuous verification process with users and numerous tests and iterations over an extended period is required.

What is more, like other nudge and gamified projects (Sunstein \& Thaler, 2008), there is always the possibility that the FOODIE initiative fails to make the expected socio-environmental impact due to lack of take up, glitches or other unforeseen issues, as happened to prior case studies of sustainable/ethical tech-based citizen engagement which incorporated gamification and taskification.

The last shortcoming concerns how FOODIE will address issues of inclusiveness and barriers to adoption. Public acceptance and adoption cannot be controlled a priori and are not necessarily guaranteed.

\section{Conclusions}

This paper underlines the urgency of tackling the concern of climate change through active public participation. Within this scope, it identifies a relevant challenge and a possible research agenda aligned with the 2030 European goals.

In particular, the paper draws on a co-design experience that emphasises the central role of design and the adoption of an interdisciplinary approach to finding a solution to complex problems. Such experience well illustrates the current role of contemporary designers, who are asked to operate in a dimension of ever-increasing complexity and fluidity. A dialogical approach shifts an individual and partial perspective to a choral, inclusive one and may enable shared and integrated solutions based on multilateral participation. In this coral perspective, design is fully entitled to play a central role in exploring innovative and creative directions to face complexity at the side of engineering, natural and social science.

We are aware that adopting such a dialogical approach will not guarantee that the FOODIE system will effectively trigger the desired behavioural change. Therefore, a constant and open confrontation with citizens will be pivotal, allowing the research team to validate or falsify all the here described assumptions.

\section{References}

Bason, C., Conway, R., Hill, D., \& Mazzucato, M. (2021), “A New Bauhaus for a Green Deal”, UCL, London.

Benner, D., Schöbel, S., \& Janson, A. (2021). "Exploring the State-of-the-Art of Persuasive Design for Smart Personal Assistants."

Bremner, C., Rodgers, P. (2013). Design Without Boundaries. Design Issues, 29(3), pp. 4-13.

Bumbac, R., Bobe, M., Procopie, R., Pamfilie, R., Giușcă, S., \& Enache, C. (2020). How zoomers' eating habits should be considered in shaping the food system for 2030-A case study on the young generation from Romania. Sustainability, 12(18), 7390. 
Cash, P.J., Hartlev, C.G., Durazo, C.B. (2017), "Behavioural Design: A Process for Integrating Behaviour Change and Design". Design Studies, 48, 96-128

Deterding, S., Dixon, D., Khaled, R., Nacke, L. (2011): From Game Design Elements to Gamefulness: Defining "Gamification". Proceedings of the 15th International Academic MindTrek Conference Envisioning Future Media Environments, 9-15

Diethelm, K., Jankovic, N., Moreno, L. A., Huybrechts, I., De Henauw, S., De Vriendt, T., ... \& Kersting, M. (2012). Food intake of European adolescents in the light of different food-based dietary guidelines: results of the HELENA (Healthy Lifestyle in Europe by Nutrition in Adolescence) Study. Public health nutrition, 15(3), 386-398.

Figueiredo Nascimento, S., Cuccillato, E., Schade, S., \& Guimarães Pereira, A. (2016). Citizen engagement in science and policy-making. Luxembourg: Publications Office of the European Union.

Herring, H., and Roy, R. (2007), "Technological Innovation, Energy Efficient Design and the Rebound Effect". Technovation, 27(4), 194-203

Maccani G., Goossensen M., Righi V., Creus J. and Balestrini M., Scaling up Citizen Science - What are the factors associated with increased reach and how to lever them to achieve impact, Publications Office of the European Union, Luxembourg, 2020, ISBN 978-92-76-25157-6, doi:10.2760/00926, JRC122219

Lynch D., Kordis P. L. (1988). Strategy of the Dolphin: Scoring a Win in a Chaotic World. William Morrow \& Co.

Mirande Y., Henchoz N. (2014). Design for Innovative Technology. From Disruption to Acceptance. Lausanne, Switzerland: Epfl Press/Routledge.

Naeem, U., Islam, S., Sharif, M., Sudakov, S., Azam, M. A. (2017). Taskification - Gamification of Tasks. UbiComp '17: Proceedings of the 2017 ACM International Joint Conference on Pervasive and Ubiquitous Computing and Proceedings of the 2017 ACM International Symposium on Wearable ComputersSeptember 2017 Pages 631-634 https://doi.org/10.1145/3123024.3124423

Nascimento, S., Cuccillato, E., Schade, S., \& Guimarães Pereira, A. (2016). Citizen engagement in science and policy-making. Luxembourg: Publications Office of the European Union

Poore, J., \& Nemecek, T. (2018). Reducing food's environmental impacts through producers and consumers. Science, 360(6392), 987-992

Ramo S. (1969). Cure for Chaos. McKay

Ranjan M.P., (2009), What is Design? Philosophy of Design and emerging insights withunfolding opportunities for the knowledge economy, National Institute of Design, Ahmedabad-India

Ritchie, $\mathrm{H}$ and Roser, M. (2020). "Environmental impacts of food production". Published online at OurWorldlnData.org. Retrieved from: 'https://ourworldindata.org/environmental-impacts-offood' [Online Resource]

Schöbel, S.; Ernst, S. -J.; Söllner, M. \& Leimeister, J. M. (2017): More than the Sum of its Parts Towards Identifying Preferred Game Design Element Combinations in Learning Management Systems. In: International Conference on Information Systems (ICIS). Seoul, South Korea

Thaler R., Sunstein C. (2008). Nudge: Improving Decisions about Health, Wealth, and Happiness. Penguin Group USA

Tromp, N., \& Hekkert, P. (2018). Designing for society: Products and services for a better world. Bloomsbury Publishing.

Tromp, N., Hekkert, P., Verbeek, P.P. (2011), “Design for Socially Responsible Behavior: a Classification of Influence Based on Intended User Experience". Design Issues, 27(3), 3-19.

Uibu, K., and Kikas, E. (2014). Authoritative and authoritarian-inconsistent teachers' preferences for teaching methods and instructional goals. Education 42, 5-22. doi:

10.1080/03004279.2011.618808 
United Nations (2019). The Sustainable Development Goals Report 2019. Retrieved from: https://unstats.un.org/sdgs/report/2019/The-Sustainable-Development-Goals-Report-2019.pdf [Online Resource]

United Nations, Economic and Social Council (2020). Progress towards the Sustainable Development Goals Report of the Secretary-General. Retrieved from:

https://sustainabledevelopment.un.org/content/documents/26158Final_SG_SDG_Progress_Repor t_14052020.pdf [Online Resource]

Varumo, L., Yaneva, R., Koppel, T., Koskela, I., Garcia, M., Sozzo, S., Morello, E. and Dictor, M., 2020. Perspectives on Citizen Engagement for the EU Post-2020 Biodiversity Strategy: An Empirical Study. Sustainability, 12(4), p.1532.

Vaute, V. (2018), "Recycling is not the Answer to the E-Waste Crisis." Forbes

Author Bios:

Carmen Bruno. Ph.D. in Design and researcher at Politecnico di Milano Her research focuses on the influences of emerging tech on creativity and merges a human-centered approach, design thinking, and co-design methodologies to facilitate radical innovation. She took part in EU and national projects.

Venere Ferraro is Assistant Professor at the Design Department of Politecnico di Milano. Using a user-centred approach, her research activity focuses on interaction design practices and how to exploit the potential of disruptive technologies to change users' behaviour.

Lucia Rampino, full professor at Politecnico di Milano, is an architect and Ph.D. in Industrial Design. Her core field of research is product design, with a focus on theories of design and the nature of design processes, particularly as they pertain to product innovation.

Susanna Testa, Ph.D. in Design, is Assistant Professor at the Design Department of Politecnico di Milano. Her research focuses on interaction and technological innovation within the field of fashion, benchmarking state-of-the-art initiatives, technologies, and products related to the fashion ecosystem. 